\title{
Quanto vale a informação? Calculando o valor econômico dos serviços de uma biblioteca
}

How much is information worth? Calculating the economic value of a library's services

Maira Nani França, Kelma Patrícia de Souza, Patrícia de Oliveira Portela

Universidade Federal de Uberlândia

\section{RESUMO}

Os benefícios dos serviços oferecidos por uma unidade informacional têm sido caracterizados pelos resultados desejados como, por exemplo, a resposta efetiva de uma questão pelo usuário sendo os valores constituídos de dados bastantes concretos se considerados em termos monetários, ou seja, qual é o custo para disponibilizar tais serviços. Atribuir e medir valor a cada um dos serviços informacionais oferecidos pelas bibliotecas universitárias é uma das tarefas gerenciais mais desafiadoras e menos aplicadas nos ambientes informacionais. Com este trabalho objetiva-se atribuir valor econômico aos serviços prestados por uma biblioteca universitária brasileira, a fim de desenvolver uma ferramenta que venha auxiliar os gestores nos processos de tomada de decisão e avaliação das unidades informacionais visando a garantia da qualidade dos serviços prestados.

PALAVRAS-Chave: Custo da informação. Serviço de informação. Biblioteca universitária. planejamento. Avaliação. Universidade Federal de Uberlândia.

\section{ABSTRACT}

The benefits of the services offered by an informational unit have been characterized by the desired outcome, such as the effective response from a user. These values are made up of enough concrete data if expressed in monetary terms, that is, finding out which is the cost to provide such services. Assigning value to each of the information services offered by university libraries and measuring it are one of the most challenging and less applied managerial tasks in information environments. This paper aims to assign economic value to the services provided by a Brazilian university library, developing a tool that will assist managers in decision -making and evaluation of informational units in order to guarantee the quality of services provided.

KEYWORDS: Information costs. Information services. University library. Planning. Evaluation. Federal University of Uberlândia.

\section{Correspondência}

${ }^{1}$ Maira Nani França

Universidade Federal de Uberlândia.

Uberlândia, MG.

Email: mairanani@hotmail.com

ORCID: http://orcid.org/0000-0002-7636-8966

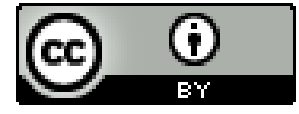

JITA: FC.Finance 


\section{INTRODUÇÃ̃o}

Também chamada de "era da informação e do conhecimento", a era pós-industrial se diferencia das demais perceptivelmente no setor econômico de modo especial em serviços, tecnologia e desenvolvimento social. Sua organização acontece em torno da informação, do conhecimento, da comunicação e do acesso aos seus serviços e produtos. Acompanha-se o crescimento vertiginoso do setor quaternário da economia responsável pela produção, processamento e distribuição de mercadorias da informação. Setor altamente intelectualizado que inclui investigação, desenvolvimento e inovação. A informação é um insumo utilizado por todas as organizações e, quando bem gerenciada, torna-se um recurso estratégico, essencial para o processo de tomada de decisão. Neste contexto os gestores das bibliotecas universitárias, para promover o acesso à informação por meio de produtos, serviços e difusão da produção intelectual acompanhando as mudanças tecnológicas, culturais e sociais, são desafiados a planejar o futuro, de modo inovador buscando nova maneira de se reinventar por meio de novos modelos de gestão.

A gestão da informação e, consequentemente, a gestão do conhecimento são modelos que passaram a ser discutidos e registrados na literatura a partir da década de 1980 (MARCHIORI, 2014) e que têm ocupado espaço cada vez mais relevante, nas unidades de informação por preocupar-se em investir na capacidade profissional de se produzir melhores resultados, de forma otimizada para se atingir os objetivos propostos e as atividades programadas identificando as necessidades de informação, a busca, o uso e o seu compartilhamento (LEITE; SOUZA, 2014, p. 12).

Em qualquer modelo de gestão o planejamento é uma prática indispensável para o exercício da administração. Sendo apontado por Almeida (2005, p. 2) como um "processo contínuo, permanente e dinâmico que fixa objetivos, define linhas de ação, detalha as etapas para atingi-los e prevê os recursos necessários à execução desses objetivos”. Dentre as diversas etapas do planejamento a autora afirma que a avaliação permite aferir o sucesso na implementação da proposta e definir novos objetivos e metas. O Dicionário de Biblioteconomia e Arquivologia define avaliação como "mensuração quantitativa e qualitativa do grau de qualidade do acervo, dos serviços e programas de uma biblioteca [...] em relação ao nível de atendimento das necessidades dos usuários" (AVALIAÇÃO, 2008, p. 41). Garantir a qualidade de um serviço oferecido é uma estratégia fundamental do processo de avaliação, que engloba diversos instrumentos como dados estatísticos, indicadores de qualidade (critérios), pesquisas com a percepção dos usuários, planilha para calcular o valor dos produtos e serviços, dentre outros. Como exemplo de indicadores de qualidade destaca-se a ISO 11620 que objetiva "endossar o uso dos indicadores de desempenho em relação à qualidade dos serviços nas bibliotecas e para disseminar conhecimentos sobre como conduzir medidas de desempenho" (INTERNATIONAL STANDARD ORGANIZATION, 2014, p. 5, tradução nossa). Outro instrumento que contribui para análise e avaliação de unidades

\begin{tabular}{l|l|l|l|l|l} 
(C) RDBCI: Rev. Digit. Bibliotecon. Cienc. Inf. & Campinas, SP & v.15 & n.1 & p. 265-281 & jan./abr. 2017 \\
\hline
\end{tabular}


informacionais é o Return On Investiment (ROI), definido pela University of West Florida como a relação entre o total do retorno econômico e do investimento em bibliotecas públicas (UNIVERSITY OF WEST FLORIDA, 2013). A American Library Association (ALA), em sua página eletrônica ${ }^{1}$, apresenta diversas bibliotecas que utilizam a metodologia ROI, com destaque para British Library, Carnegie Library of Pittsburgh, Florida Public Libraries dentre outras. O processo de avaliação exige a adequação da unidade informacional às necessidades de seus usuários e aos padrões determinados pela profissão visando a satisfação daquele que utiliza os serviços e a realização daqueles que o oferecem.

Neste contexto, este trabalho objetiva atribuir valor econômico aos serviços prestados por uma biblioteca universitária brasileira, a fim de desenvolver um protótipo de ferramenta que venha auxiliar os gestores nos processos de tomada de decisão e avaliação das unidades informacionais visando a garantia da qualidade dos serviços prestados.

\section{REVISÃo DE LITERATURA}

Chamamos de serviço o desempenho de qualquer trabalho, préstimo, proveito, utilidade, interligado ou não a um produto físico representando a intangibilidade de um bem. A prestação de serviços por exemplo, não concede ao adquirente a posse exclusiva de um benefício exceto, nos casos que existe contrato de exclusividade. Embora de natureza intangível os serviços prestados por muitos setores exigem grandes estruturas e equipamentos físicos e consomem grandes quantidades de recursos.

Como a informação é matéria-prima das bibliotecas, um serviço de informação consiste em uma atividade de identificação, aquisição, processamento e transmissão de informação e, por muitas vezes no fornecimento de um produto de informação. Além da característica de intangibilidade o serviço de informação é heterogêneo, simultâneo e volátil, o que implica na atenção especial em gestão de processos (BARBALHO, 1997; DHOLAKIA; MUNDORF; DHOLAKIA, 1997), como no caso das bibliotecas. Dentre os serviços mais comuns oferecidos pelas bibliotecas destacam-se o empréstimo nas mais diversas modalidades, a comutação bibliográfica, a elaboração de fichas catalográficas, as orientações para pesquisa em bases de dados, a normalização de trabalhos acadêmicos, dentre outros. Para identificar o preço justo pelo serviço oferecido, uma série de variáveis devem ser consideradas como por exemplo, o ambiente (aluguel do espaço), o funcionário responsável pelo atendimento, etc.

A relação custo-benefício de um produto ou serviço é a análise referente entre o que se gasta e o que se recebe como lucro ${ }^{2}$. Para Balbinoto Neto ([2016]), esta relação ocorre

\footnotetext{
${ }^{1}$ Cf. http://www.ala.org/research/librariesmatter/taxonomy/term/129.

${ }^{2}$ Nota das autoras: Como as unidades de informação não visam o lucro, a proposta para precificar os serviços informacionais limita-se à identificação de custo. Outro fator limitador não considerado no estudo é a

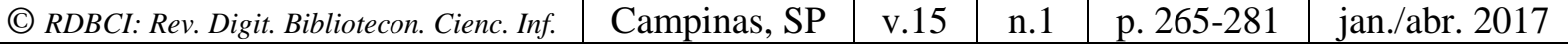


"quando duas ou mais estratégias são comparadas considerando-se suas consequências e custos." Trazendo o termo para as unidades de informação, a análise deve justificar a permanência de determinado serviço em função dos benefícios que resultam dele. Os benefícios do serviço de informação têm sido caracterizados pelos resultados desejados como por exemplo a resposta efetiva de uma questão pelo usuário sendo os custos constituídos de dados bastantes concretos, se considerados em termos monetários, ou seja, quanto se gastou para disponibilizar tais serviços.

De acordo com Lancaster (1996), para se determinar o valor real do serviço de informação deve-se levar em conta todos os custos inclusive, aqueles em que se incluem os usuários pois, não se deve dizer que o tempo gasto no uso dos serviços de informação não tem custo. Para o autor uma relação custo-benefício pode ser melhorada no sentido de aumentar os benefícios sem aumentar os custos ou ainda, reduzir os custos sem reduzir os benefícios.

[...] os benefícios dos serviços de informação costumam ser intangíveis, e porque não podem ser expressados facilmente na mesma unidade, como os custos (por exemplo, em valores monetários), os verdadeiros estudos sobre custo-benefício são praticamente irrealizáveis em nosso campo (LANCASTER, 1996, p. 1).

Embora reconhecendo que os benefícios dos serviços de informação não podem ser expressos com igual infalibilidade dos custos, ainda na tentativa de identificá-los nas mesmas unidades de medidas em que se expressam os custos, ou seja, em valor monetário, acredita-se numa análise de resultados aproximada que não deve ser desprezada quando se planeja as ações de uma biblioteca, pelo contrário tal avaliação é fundamental na tomada de decisão referente a manter ou adquirir determinado tipo de serviço.

Identificar o benefício que o trabalho desenvolvido em unidades informacionais representa para a sociedade, considerando os aspectos econômicos, sempre tem sido um grande desafio para os gestores. Apesar de Lancaster (1996) defender que os estudos sobre custo-benefício são praticamente irrealizáveis em nossa área ou indica que tentativas desta natureza, com variados graus de sucesso, têm sido realizadas como exemplificadas a seguir. A Rede de Bibliotecas do Conselho Superior de Investigações Científicas da Espanha (CSIC, 2012) aponta os estudos de retorno sobre o investimento aplicado às bibliotecas, como uma das tentativas para suprir esta demanda.

A Massachusetts Library Association (MLA) foi a pioneira na criação de uma planilha para calcular e divulgar o valor dos serviços oferecidos pelas bibliotecas, posteriormente a Chelmsford Public Library ${ }^{3}$ adaptou a calculadora da MLA e a disponibilizou para acesso via Web e permitiu o compartilhamento da mesma para outras instituições. De acordo com o

intangibilidade do bem. Por exemplo, ao definir o custo de um Empréstimo Entre Bibliotecas (EEB) de um livro pertencente ao acervo de uma biblioteca estrangeira, poderia (e deveria) ser contabilizado o fato de que para conseguir o serviço o interessado teria que viajar para os EUA, por exemplo.

3 Cf. http://www.chelmsfordlibrary.com/library info/calculator.html.

\begin{tabular}{|c|c|c|c|c|c|}
\hline (C) RDBCI: Rev. Digit. Bibliotecon. Cienc. Inf. & Campinas, SP & $\mathrm{v} .15$ & n. 1 & p. $265-281$ & jan./abr. 2017 \\
\hline
\end{tabular}


CSIC (2012) a calculadora é uma ferramenta desenvolvida para auxiliar as bibliotecas na compreensão e divulgação do valor dos serviços prestados sendo possível expansão, adaptação e correção de propostas de acordo com as necessidades de cada biblioteca. Atualmente a ferramenta é utilizada por várias bibliotecas nos Estados Unidos, tais como: $A L A^{4}$, Vermont Library Association ${ }^{5}$, Maine State Library ${ }^{6}$, Sno-Isle Libraries ${ }^{7}$, National Network of Libraries of Medicine e New York Library Association? ${ }^{8}$.

Em 2010, a Rede de Bibliotecas do CSIC divulgou a iniciativa de adaptação da ferramenta da MLA, para quantificar economicamente o benefício resultante da utilização dos serviços propostos pelas bibliotecas. Em um primeiro momento foram definidos os tipos de serviços, a unidade de medida adotada para contabilizar a sua utilização, o preço estimado do serviço (ano base 2011), a fonte usada para calculá-lo e a fórmula/dados necessários para definição (CSIC, 2012) (Quadro 1). Quanto à coleta dos dados,

[...] os cálculos podem ser feitos por bibliotecas ou redes de bibliotecas para o ano em curso ou por períodos mais curtos, como uma amostragem do valor dos serviços prestados, ou pelos usuários para saber quanto custaria para adquirir estes recursos de uma só vez ou ao longo de um período de tempo (CSIC, 2012, tradução nossa).

Os serviços informacionais considerados pela rede espanhola foram: empréstimo de livros, livros e revistas consultados ${ }^{10}$, reprografia, comutação bibliográfica, empréstimo entre bibliotecas, uso de salas de estudo ou reunião, formação de usuários, capacitação de bibliotecários, uso de computadores, downloads de artigos científicos e documentos da biblioteca digital e serviços de referência, para os quais foi atribuída uma unidade de medida (volumes, fotocópias, originais, artigos, horas, assistentes, downloads e consultas (Quadro 1).

Para cada um dos serviços são apresentados preços estimados. Os preços definidos podem ser aplicáveis em bibliotecas ou redes de bibliotecas que tenham características semelhantes à Rede de Bibliotecas do CSIC (2012). Visando a consistência dos dados fornecidos com a realidade econômica da biblioteca e do ambiente em que se insere, os autores destacam a necessidade de atualização constante dos preços. O CSIC (2012) destaca ainda que para calcular cada um dos preços foram estabelecidas fontes que refletem melhor o custo de cada serviço informacional. A maioria dos preços foi baseada em médias adotadas por organizações semelhantes à Rede de Bibliotecas ou aplicados por organizações e associações, de classe como (REBIUN, Sedic e COBDC) ou serviços de entrega de documento como (SUBITO, BLD, OCLC, INIST, etc.). Em alguns casos foi definido um preço estimado com base nos prestadores de serviços similares disponíveis em sítios

\footnotetext{
Cf. http://www.ala.org/advocacy/advleg/advocacyuniversity/toolkit/makingthecase/library calculator.

Cf. http://web.archive.org/web/20071010131408/http://www.vermontlibraries.org/value.html.

Cf. http://www.maine.gov/msl/services/calculator.htm.

Cf. http://www.sno-isle.org/valuecalc/

Cf. https://nnlm.gov/mcr/evaluation/calculator.html

Cf. https://www.nyla.org/max/4DCGI/cms/review.html?Action=CMS Document\&DocID=1181\&MenuKey=advocacy

10 Orientam que os dados podem ser coletados manual ou automaticamente pelo sistema de gestão da biblioteca, módulo empréstimo. Caso não sejam recolhidos sistematicamente, orientam a adoção de amostragem.

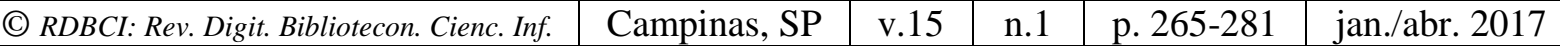


(cibercafé, aluguel de salas, etc.). As fórmulas adotadas para definição de cada preço estão listadas no Quadro 1.

\section{MÉTODO}

A metodologia adotada para desenvolvimento deste trabalho fundamentou-se nos pressupostos da pesquisa qualitativa combinada com recursos da abordagem quantitativa, de viés exploratório, na intenção de fornecer os subsídios necessários para a compreensão das questões relativas à avaliação de bibliotecas, qualidade dos serviços ofertados, levantamentos estatísticos, custo-benefício. Para Gunther (2016), o envolvimento emocional do pesquisador com o tema de investigação caracterizaria a pesquisa qualitativa, entendida como um processo de reflexão e análise da realidade, através da adoção de técnicas para melhor compreensão do objeto de estudo em seu contexto histórico ou segundo a sua estruturação, como um ato social de construção do conhecimento. Por outro lado, os recursos da abordagem quantitativa consideram os dados estatísticos expressos em quantidades, excluindo crenças e valores pessoais como fontes de influência no processo científico.

Para formular questões ou problemas, Marconi e Lakatos (1990, p. 77), apontam a aplicação da pesquisa exploratória que permite "desenvolver hipóteses, aumentar a familiaridade do pesquisador com o ambiente, fato ou fenômeno para a realização de uma pesquisa futura mais precisa ou modificar e clarificar conceitos".

A coleta de dados se deu a partir de levantamentos bibliográfico e documental pertinentes ao tema publicados em livros, artigos científicos, teses e dissertações, documentos oficiais governamentais e institucionais e demais documentos disponíveis na internet e ainda, o método de custeio, para compor uma estimativa do preço dos serviços utilizado pelo mercado. 
QUADRO 1. Precificação dos serviços informacionais da Rede de Bibliotecas del CSIC

Fonte: Adaptado de CSIC (2012).

\begin{tabular}{|c|c|c|c|c|c|}
\hline Serviço & Medida & Preço em Euro & Preço em Real & Fonte do preço & Fórmula \\
\hline Libros prestados & Volúmenes & $37,64 €$ & $\mathrm{R} \$ 151,31$ & $\begin{array}{l}\text { REBIUN: precio medio de las } \\
\text { monografías }\end{array}$ & $\begin{array}{l}\Sigma \text { Gasto en compra de monografías } / \Sigma \\
\text { Monografías compradas }\end{array}$ \\
\hline Libros consultados en sala & Volúmenes & $37,64 €$ & $\mathrm{R} \$ 151,31$ & $\begin{array}{l}\text { REBIUN: precio medio de las } \\
\text { monografías }\end{array}$ & $\begin{array}{l}\Sigma \text { Gasto en compra de monografías } / \Sigma \\
\text { Monografías compradas }\end{array}$ \\
\hline Revistas consultadas en sala & Volúmenes & $5,48 €$ & $\mathrm{R} \$ 22,03$ & REBIUN: precio medio de los artículos & $\begin{array}{l}\text { ( } \Sigma \text { Gasto en suscripción de revistas } / \Sigma \text { revistas } \\
\text { compradas }) /(4 \text { números al año x } 10 \text { artículos } \\
\text { por número) }\end{array}$ \\
\hline Reprografía o fotodocumentación & Fotocopias & $0,15 €$ & $\mathrm{R} \$ 0,60$ & CSIC: precio reproducción en A4 & Precio para fotocopias A4 \\
\hline PI originales más tarifas de PI & Originales & $45,64 €$ & $\mathrm{R} \$ 183,47$ & REBIUN: precio medio de monografías & $\begin{array}{l}\text { ( } \Sigma \text { Gasto en compra de monografías } / \Sigma \\
\text { Monografías compradas en el año) + Tarifas } \\
\text { PI para préstamo de originales }\end{array}$ \\
\hline PI artículos tarifas de PI & Artículos & $10,48 €$ & $\mathrm{R} \$ 42,13$ & REBIUN: precio medio de artículos más & $\begin{array}{l}\text { (( } \Sigma \text { Gasto en suscripción de revistas } / \Sigma \\
\text { Revistas compradas }) /(4 \text { números al año x } 10 \\
\text { artículos por número) })+ \text { Tarifas PI para copias }\end{array}$ \\
\hline Uso de salas de estudio o reunión & Horas & $15,00 €$ & $\mathrm{R} \$ 60,30$ & Precio estimado por hora & Estimación \\
\hline Formación de usuarios para socios & Asistentes & $177,00 €$ & $\mathrm{R} \$ 711,54$ & $\begin{array}{l}\text { SEDIC y COBDC: precio medio de } \\
\text { cursos }\end{array}$ & $\begin{array}{l}\Sigma \text { Precio de cursos organizados } / \Sigma \text { Cursos } \\
\text { organizados }\end{array}$ \\
\hline $\begin{array}{l}\text { Formación de bibliotecarios para } \\
\text { socios }\end{array}$ & Asistentes & $177,00 €$ & $\mathrm{R} \$ 711,54$ & $\begin{array}{l}\text { SEDIC y COBDC: precio medio de } \\
\text { cursos }\end{array}$ & $\begin{array}{l}\Sigma \text { Precio de cursos organizados } / \Sigma \text { Cursos } \\
\text { organizados }\end{array}$ \\
\hline Uso de ordenadores & Usuarios/Hora & $3,00 €$ & $\mathrm{R} \$ 12,06$ & $\begin{array}{l}\text { Cibercafés: precio medio estimado por } \\
\text { hora }\end{array}$ & Estimación \\
\hline Descargas de artículos en línea & Descargas & $13,00 €$ & $\mathrm{R} \$ 52,26$ & $\begin{array}{l}\text { SUBITO, BLD, BNF y REBIUN: precio } \\
\text { medio por envío electrónico de copias }\end{array}$ & $\begin{array}{l}\Sigma \text { Precios de los servicios de obtención de } \\
\text { documentos } / \Sigma \text { Proveedores }\end{array}$ \\
\hline Descargas de Digital.CSIC & Descargas & $13,00 €$ & $\mathrm{R} \$ 52,26$ & $\begin{array}{l}\text { SUBITO, BLD, BNF y REBIUN: precio } \\
\text { medio por envío electrónico de copias }\end{array}$ & $\begin{array}{l}\Sigma \text { Precios de los servicios de obtención de } \\
\text { documentos } / \Sigma \text { Proveedores }\end{array}$ \\
\hline Servicios de Referencia & Consultas & $15,00 €$ & $\mathrm{R} \$ 60,30$ & Precio estimado por consulta & Estimación \\
\hline
\end{tabular}

Para aproximar-se da realidade brasileira, os valores dos serviços em Euro foram convertidos para Real. Cotação de 21/04/2016. Cf. http://www4.bcb.gov.br/pec/conversao/conversao.asp.

\begin{tabular}{|c|c|c|c|c|c|}
\hline (C) RDBCI: Rev. Digit. Bibliotecon. Cienc. Inf. & Campinas, SP & v. 15 & n.1 & p. $265-281$ & jan./abr. 2017 \\
\hline
\end{tabular}


As informações referentes aos custos, bem como suas análises, são subsídios estratégicos na tomada de decisões pelos gestores na otimização do desempenho das organizações. Para a realização das análises de custo é necessária a utilização de sistemas de custeio que se referem à forma de determinar os custos dos produtos ou serviços por determinada empresa. Para esta pesquisa adotou-se o sistema de custeio baseado em atividades (ABC), que "parte do princípio de que não são os bens ou serviços que consomem recursos, mas, sim, os recursos que são consumidos pelas atividades e estas, por sua vez, são consumidas pelos bens ou serviços" (ABBAS; GONÇALVES; LEONCINE, 2003), mesclando "recursos humanos, materiais, tecnológicos e financeiros utilizados para produzir bens e serviços." (MARTINS, 2000, p. 100).

A análise e interpretação dos dados foram realizadas a partir das informações obtidas na literatura (levantamento bibliográfico e documental), confrontadas com os dados coletados (dados estatísticos de serviços oferecidos pela Biblioteca Central Santa Mônica, coletados no ano base 2015 e preços de serviços informacionais no mercado).

Considerando as indagações apontadas pelas autoras: Quanto vale os nossos serviços? Existe no Brasil alguma iniciativa desta natureza, que atribui preço aos serviços informacionais prestados pelas bibliotecas? E o fato de não ter sido identificado no universo pesquisado, nenhuma ferramenta adaptada àquelas disponibilizadas pelas bibliotecas do exterior (EUA e Espanha), surgiu a intenção de identificar as categorias e definir critérios para precificar os serviços prestados nas unidades informacionais. A definição das categorias partiu do modelo adotado pela Rede de Bibliotecas do CSIC (Quadro 1), adaptado conforme a realidade vivenciada nas bibliotecas da UFU, objeto em questão. Dentre as categorias analisadas e identificadas chegou-se às seguintes categorias: Empréstimo, Consulta, Reprografia, Comutação Bibliográfica, Acesso, Download, Uso de ambientes coletivos, Capacitação de usuários, Formação de servidores, Uso de computadores, Serviços de Referência, Catalogação na Publicação e Informações na página eletrônica.

A Biblioteca Central Santa Mônica, definida como objeto deste estudo, foi a primeira grande biblioteca da UFU construída, inaugurada em 1991 com espaço físico referente a $5.735 \mathrm{~m}^{2}$. Nesse edifício concentram-se a diretoria do SISBI/UFU, as divisões que desenvolvem os serviços internos tais como: seleção, aquisição, preparo, catalogação, classificação e tratamento de todo material informacional adquirido para as oito bibliotecas do sistema, além do acervo de obras das áreas: Ciências Exatas e da Terra, Ciências Humanas, Ciências Sociais Aplicadas, Engenharias, Linguística, Letras e Artes (UFU, 2016). Dentre os serviços oferecidos destacam-se: achados e perdidos; aquisição de material informacional; catalogação na publicação; abertura de cadastro; empréstimo de material informacional; empréstimo de netbooks, tablets e e-readers; empréstimo entre bibliotecas; nada consta; renovação; reserva; doação de material informacional; comutação bibliográfica; guarda-volumes; levantamento bibliográfico; listagem de acervo; normalização; recebimento de comissão do MEC; submissão de teses ou dissertações à BDTD; sugestões de obras literárias: treinamentos; VídeoSaúde Fiocruz (indicação de vídeos na área da saúde); 
autosserviços (devolução, empréstimo, escaneamento de textos; ilha multimídia; ilha de pesquisa; laboratórios colaborativos; aplicativo do software de gerenciamento do SISBI/UFU para dispositivo móvel; rede sem fio wi-fi; SIGAMI (Sistema de Gerenciamento de Aquisição de Material Informacional; vídeoconferência; sistema de áudio 7 em 1; tecnologias assistivas; sala 24 horas; sala de audiovisual; sala de reserva; ambiente para utilização de materiais audiovisuais.

Enfim, este trabalho é um estudo preliminar a partir do qual pretende-se elaborar um plano de aplicação para desenvolver, em parceria com o Centro de Tecnologia da Informação (CTI), uma ferramenta para calcular o valor dos serviços oferecidos pelas bibliotecas da UFU que será instalada na página eletrônica do SISBI/UFU de modo que outras instituições possam se beneficiar da mesma. Por se tratar de uma universidade pública, a intenção é que o código fonte da Calculadora seja disponibilizado aos interessados para que façam adaptações conforme as peculiaridades de sua instituição corroborando os princípios do Ministério do Planejamento, Orçamento e gestão (MPOG) (BRASIL, [2016a]) de gestão de recursos e gastos de informática mais racionalizada e, ampliação de parcerias e reforço da política de software livre no setor público. A Calculadora será um produto tangível ${ }^{11}$, resultado do estudo da descrição dos serviços oferecidos pelas bibliotecas e do levantamento do valor destes serviços.

\section{RESULTADOS}

A fim de cumprir o objetivo proposto para este trabalho atribuir valor econômico aos serviços prestados por uma biblioteca universitária, a partir dos serviços indicados pela Rede de Bibliotecas do CSIC (Quadro 1) confrontados com a realidade vivenciada na Biblioteca Central Santa Mônica da UFU foram definidos os seguintes serviços informacionais ${ }^{12}$ para compor a realidade de uma biblioteca universitária brasileira:

a) empréstimo de livros, DVD, CD, partituras, EEB e EIB: indica o número de "exemplares" emprestados, no período de tempo analisado, conforme dados estatísticos da biblioteca;

b) empréstimo de dispositivos móveis: indica o número de "unidades" emprestadas, no período de tempo analisado, conforme dados estatísticos da biblioteca;

c) livros consultados: indica o número de "exemplares" consultados nas dependências da biblioteca, por meio de coleta manual;

d) revistas e jornais consultados: indica o número de "fascículos" consultados nas dependências da biblioteca;

e) reprografia: indica o número de "páginas" escaneadas na biblioteca;

f) comutação bibliográfica: indica o número "artigos" solicitados;

g) acesso aos audio books e às músicas: indica o número de acessos;

11 Algo que possa ser utilizado por outra pessoa, não apenas como informação, mas com instruções ou manual de utilização, com exemplos de aplicações (UFU, 2014).

12 As unidades de medida estabelecidas estão com o destaque sublinhado em cada um dos serviços.

\begin{tabular}{|c|c|c|c|c|c|}
\hline (C) RDBCI: Rev. Digit. Bibliotecon. Cienc. Inf. & Campinas, SP & v.15 & n. 1 & p. $265-281$ & jan./abr. 2017 \\
\hline
\end{tabular}


h) "download" de e-books e documentos de bases de dados assinadas e "acesso" a artigos do Portal Capes e, teses e dissertações da BDTD: indica o número de itens baixados;

i) uso de salas de estudo, multimídias e de videoconferência: indica o número de "horas" que os usuários utilizam estes ambientes, conforme dados coletados automaticamente;

j) capacitação: indica o número total de usuários capacitados (em grupo ou individualmente) ("participações") para utilizar os serviços e produtos (visita orientadas, pesquisa em bases de dados e normalização) da biblioteca;

k) formação: indica o número total de servidores (bibliotecários e assistentes) que frequentam cursos de formação continuada e/ou participam de eventos na área de atuação ("participações");

1) uso de computadores: indica o número de "horas" que os usuários utilizam os computadores da biblioteca para pesquisa acadêmica conforme dados coletados por amostragem

m) serviços de referência: indica o número total de atendimentos realizados pelo serviço de referência (orientação no uso do equipamento de autoempréstimo e do catálogo online, sobre como efetuar pagamento de multa, na localização de livros nas estantes, informações gerais sobre a universidade e os serviços da biblioteca, entre outros), conforme coleta de dados realizada manualmente;

n) catalogação na publicação: indica o número total de "fichas catalográficas" elaboradas pelos bibliotecários;

o) informação por meio da página eletrônica: indica o número de "horas" dedicadas para atualização da página eletrônica da biblioteca, por um bibliotecário (Quadro 2).

Para cada um dos serviços foi estabelecido um preço estimado baseado em valores praticados pelas empresas prestadoras de serviços para o SISBI e para a UFU ou aplicados por organizações e associações de classe como a Associação de Bibliotecários de Minas Gerais (ABMG) ou serviços de entrega de documento como o COMUT. Em alguns casos, foi definido um preço estimado com base nos prestadores de serviços similares disponíveis no mercado (cibercafés, aluguel de salas, etc.). As fórmulas adotadas para definição de cada preço são apresentadas no Quadro 2.

No Quadro 2, as categorias em destaque (vermelho) não foram consideradas na aplicação da pesquisa na Biblioteca Central Santa Mônica, no período analisado, por falta de dados consistentes no momento de coleta dos dados, porém, estão descritas uma vez que as mesmas serão consideradas na ferramenta a ser desenvolvida, próxima etapa deste estudo. 
QUADRO 2. Precificação dos serviços informacionais da Biblioteca Central Santa Mônica/UFU

\begin{tabular}{|c|c|c|c|c|c|}
\hline \multicolumn{2}{|r|}{ Serviço } & \multirow{2}{*}{$\begin{array}{r}\text { Medida } \\
\text { Exemplares }\end{array}$} & \multirow{2}{*}{$\begin{array}{c}\text { Preço } \\
\mathrm{R} \$ 176,15 \\
\end{array}$} & \multirow{2}{*}{\begin{tabular}{|l|}
\multicolumn{1}{|c|}{ Fonte de consulta - Valor } \\
SISBI/UFU: preço médio de itens \\
solicitados (2015)
\end{tabular}} & \multirow{2}{*}{$\begin{array}{l}\text { Fórmula } \\
\Sigma \text { Valor total dos pedidos de livros nacionais e } \\
\text { estrangeiros } / \Sigma \text { Número de exemplares }\end{array}$} \\
\hline \multirow{7}{*}{ Empréstimo } & Livros & & & & \\
\hline & DVD & Exemplares & $\mathrm{R} \$ 90,33$ & $\begin{array}{l}\text { SISBI/UFU: preço médio de itens } \\
\text { solicitados (2014) }\end{array}$ & $\begin{array}{l}\Sigma \text { Valor total de DVD empenhados / } \Sigma \text { Número } \\
\text { de exemplares adquiridos }\end{array}$ \\
\hline & $\mathrm{CD}$ & Exemplares & $\mathrm{R} \$ 99,87$ & $\begin{array}{l}\text { SISBI/UFU: preço médio de itens } \\
\text { solicitados (2012) }\end{array}$ & $\begin{array}{l}\Sigma \text { Valor total de CD empenhados / } \Sigma \text { Número } \\
\text { de exemplares adquiridos }\end{array}$ \\
\hline & Partituras & Exemplares & $\mathrm{R} \$ 65,82$ & $\begin{array}{l}\text { SISBI/UFU: preço médio de itens } \\
\text { solicitados (2014) }\end{array}$ & $\begin{array}{l}\Sigma \text { Valor total de partituras empenhadas / } \Sigma \\
\text { Número de exemplares adquiridos }\end{array}$ \\
\hline & Empréstimo Interbibliotecas UFU (EIB) & Exemplares & $\mathrm{R} \$ 176,15$ & $\begin{array}{l}\text { SISBI/UFU: preço médio de itens } \\
\text { solicitados (2015) }\end{array}$ & $\begin{array}{l}\Sigma \text { Valor total dos pedidos de livros nacionais e } \\
\text { estrangeiros / } \Sigma \text { Número de exemplares }\end{array}$ \\
\hline & Empréstimo Entre Bibliotecas (EEB) & Exemplares & $\mathrm{R} \$ 176,15$ & $\begin{array}{l}\text { SISBI/UFU: preço médio de livros } \\
\text { solicitados (2015) }\end{array}$ & $\begin{array}{l}\Sigma \text { Valor total dos pedidos de livros nacionais e } \\
\text { estrangeiros / } \Sigma \text { Número de exemplares }\end{array}$ \\
\hline & Dispositivos móveis & Unidades & $\mathrm{R} \$ 762,94$ & $\begin{array}{l}\text { SISBI/UFU: preço médio de itens } \\
\text { adquiridos (2013) }\end{array}$ & $\begin{array}{l}\Sigma \text { Valor total de equipamentos empenhados } / \Sigma \\
\text { Número de unidades adquiridos }\end{array}$ \\
\hline \multirow{3}{*}{ Consulta } & Livros & Exemplares & $\mathrm{R} \$ 176,15$ & $\begin{array}{l}\text { SISBI/UFU: preço médio de livros } \\
\text { solicitados (2015) }\end{array}$ & $\begin{array}{l}\Sigma \text { Valor total dos pedidos de livros nacionais e } \\
\text { estrangeiros } / \Sigma \text { Número de exemplares }\end{array}$ \\
\hline & Revistas & Fascículos & $\mathrm{R} \$ 0,00$ & $\begin{array}{l}\text { SISBI/UFU: preço médio de itens } \\
\text { assinados }\end{array}$ & $\begin{array}{l}\Sigma \text { Valor das assinaturas/renovações } \\
\text { empenhadas } / \Sigma \text { Número de fascículos } \\
\text { adquiridos }\end{array}$ \\
\hline & Jornais & Fascículos & $\mathrm{R} \$ 0,00$ & $\begin{array}{l}\text { SISBI/UFU: preço médio de itens } \\
\text { assinados }\end{array}$ & $\begin{array}{l}\Sigma \text { Valor das assinaturas/renovações } \\
\text { empenhadas / } \Sigma \text { Número de fascículos } \\
\text { adquiridos }\end{array}$ \\
\hline \multicolumn{2}{|l|}{ Reprografia } & Páginas & $\mathrm{R} \$ 0,10$ & $\begin{array}{l}\text { UFU (Bloco 5O - Campus Santa } \\
\text { Mônica): preço da cópia (2015) }\end{array}$ & Valor da cópia por página \\
\hline \multicolumn{2}{|c|}{ Comutação bibliográfica } & Artigos & $\mathrm{R} \$ 6,60$ & COMUT: valor médio por artigo (2016) & $\begin{array}{l}\text { Valor cobrado pelo Comut ( } \mathrm{R} \$ 2,20 \text { a cada } 5 \\
\text { páginas/artigo) - Média: } 15 \text { páginas/artigo }\end{array}$ \\
\hline \multirow{2}{*}{ Acesso } & Audio books & Acesso & $\mathrm{R} \$ 2,18$ & $\begin{array}{l}\text { SISBI/UFU: valor da assinatura da base } \\
\text { de dados Naxos Spoken Library (2015) }\end{array}$ & $\begin{array}{l}\Sigma \text { Valor da assinatura/aquisição / } \Sigma \text { Número de } \\
\text { títulos assinados/adquiridos }\end{array}$ \\
\hline & Música & Acesso & $\mathrm{R} \$ 3,49$ & $\begin{array}{l}\text { Itunes e Amazon: preço médio por } \\
\text { download (2016) }\end{array}$ & Valor médio de cada download \\
\hline Download & E-books & Downloads & $\mathrm{R} \$ 101,81$ & $\begin{array}{l}\text { SISBI/UFU: preço médio de itens } \\
\text { solicitados (2013) }\end{array}$ & $\begin{array}{l}\Sigma \text { Valor total de } e \text {-books empenhados } / \Sigma \\
\text { Número de títulos adquiridos }\end{array}$ \\
\hline
\end{tabular}




\begin{tabular}{|c|c|c|c|c|c|}
\hline & Serviço & Medida & Preço & Fonte de consulta - Valor & Fórmula \\
\hline & Documentos - Bases de Dados assinadas & Downloads & $\mathrm{R} \$ 6,60$ & $\begin{array}{l}\text { SISBI/UFU: valor da assinatura das } \\
\text { bases de dados Naxos Sheet Library, } \\
\text { Jstor e UpToDate(2015) }\end{array}$ & $\begin{array}{l}\text { Valor cobrado pelo Comut ( } \mathrm{R} \$ 2,20 \text { a cada } 5 \\
\text { páginas/artigo) - Média: } 15 \text { páginas/artigo }\end{array}$ \\
\hline & $\begin{array}{l}\text { Artigos - Portal de Periódicos } \\
\text { Capes/MEC }\end{array}$ & Downloads & $\mathrm{R} \$ 6,60$ & COMUT: valor médio por artigo (2016) & $\begin{array}{l}\text { Valor cobrado pelo Comut (R } \$ 2,20 \text { a cada } 5 \\
\text { páginas/artigo) - Média: } 15 \text { páginas/artigo } \\
\end{array}$ \\
\hline & $\begin{array}{l}\text { Biblioteca Digital de Teses e } \\
\text { Dissertações }\end{array}$ & Downloads & $\mathrm{R} \$ 39,60$ & $\begin{array}{l}\text { COMUT: valor médio por } \\
\text { dissertação/tese (2016) }\end{array}$ & $\begin{array}{l}\text { Valor cobrado pelo Comut (R\$2,20 a cada } 5 \\
\text { páginas/trabalho) - Média: } 90 \text { páginas/tese ou } \\
\text { dissertação }\end{array}$ \\
\hline \multicolumn{2}{|c|}{$\begin{array}{l}\text { Uso de salas de estudo em grupo, multimídia e de } \\
\text { videoconferência }\end{array}$} & Horas & $\mathrm{R} \$ 35,00$ & $\begin{array}{l}\text { B2B Virtual Office: preço do aluguel } \\
\text { da sala por hora (2016) }\end{array}$ & $\begin{array}{l}\text { Valor médio cobrado, por hora, por uma sala } \\
\text { climatizada e equipada com data show, telão, } \\
\text { flip chart, quadro branco e internet. }\end{array}$ \\
\hline \multirow{3}{*}{ Capacitação } & Visita orientada & Participantes & $\mathrm{R} \$ 11,25$ & $\begin{array}{l}\text { Content Mind: preço médio de cursos } \\
(2016)\end{array}$ & $\begin{array}{l}\text { Valor médio de curso de capacitação na área, } \\
\text { por hora }\end{array}$ \\
\hline & Bases de dados & Participantes & $\mathrm{R} \$ 10,00$ & $\begin{array}{l}\text { Content Mind: preço de curso na área } \\
(2016)\end{array}$ & $\begin{array}{l}\text { Valor médio de curso de capacitação na área, } \\
\text { por hora }\end{array}$ \\
\hline & Normalização & Participantes & $\mathrm{R} \$ 8,33$ & $\begin{array}{l}\text { Content Mind: preço médio de cursos } \\
(2016)\end{array}$ & $\begin{array}{l}\text { Valor médio de curso de capacitação na área, } \\
\text { por hora }\end{array}$ \\
\hline \multirow[b]{2}{*}{ Formação } & Bibliotecários e assistentes & Participantes & $\mathrm{R} \$ 0,00$ & $\begin{array}{l}\text { Divisão de Capacitação (DICAP)/UFU: } \\
\text { preço médio de cursos }\end{array}$ & $\begin{array}{l}\Sigma \text { Valor investido em curso de capacitação / } \Sigma \\
\text { Número de participações }\end{array}$ \\
\hline & Participação em eventos e reuniões & Participações & $\begin{array}{r}\mathrm{R} \$ \\
1.303,57 \\
\end{array}$ & $\begin{array}{l}\text { Sistema de Concessão de Diárias e } \\
\text { Passagens (SCDP)/UFU: preço médio } \\
\text { de diárias, passagens e inscrição em } \\
\text { eventos (2015) }\end{array}$ & $\begin{array}{l}\Sigma \text { Valor investido em participação em eventos / } \\
\Sigma \text { Número de participações }\end{array}$ \\
\hline \multicolumn{2}{|c|}{ Uso de computadores para pesquisa acadêmica } & Horas & $\mathrm{R} \$ 3,00$ & $\begin{array}{l}\text { Cibercafés: precio medio estimado por } \\
\text { hora (2016) }\end{array}$ & Valor médio cobrado, por hora, em cibercafé \\
\hline \multicolumn{2}{|c|}{ Serviços de Referência } & Atendimentos & $\mathrm{R} \$ 22,92$ & $\begin{array}{l}\text { Média remuneração/hora bibliotecário } \\
\text { (nível E) - Edital UFU (2015) }\end{array}$ & $\begin{array}{l}\text { Média da remunerção de um bibliotecário, por } \\
\text { hora }\end{array}$ \\
\hline \multicolumn{2}{|c|}{ Catalogação na publicação } & Fichas & $\mathrm{R} \$ 132,00$ & ABMG (2016) & $15 \%$ do salário mínimo \\
\hline \multicolumn{2}{|c|}{ Informações por meio da página eletrônica } & Horas & $\mathrm{R} \$ 22,92$ & $\begin{array}{l}\text { Média remuneração/hora bibliotecário } \\
\text { (nível E) - Edital UFU (2015) }\end{array}$ & $\begin{array}{l}\text { Média da remunerção de um bibliotecário, por } \\
\text { hora }\end{array}$ \\
\hline
\end{tabular}

Fonte: adaptado de CSIC (2012).

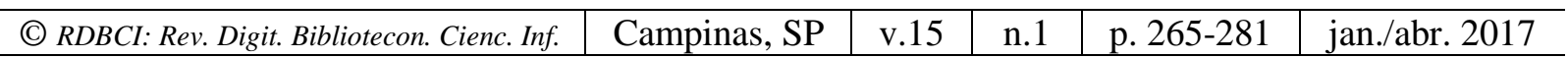


A Tabela 1 mostra que o valor dos serviços informacionais da Biblioteca Central Santa Mônica referente ao ano de 2015, ultrapassou R $\$ 30.000 .000,00$. Ressalta-se que 2015 foi um ano atípico uma vez que a biblioteca ficou fechada no período de 17/03 a 25/05/2015, em função da greve dos servidores técnico-administrativos em educação da Universidade Federal de Uberlândia (UFU), o que impactou na média anual em relação aos outros anos e, consequentemente no valor total dos serviços prestados, no ano em questão.

TABELA 1. Valoração dos serviços informacionais da Biblioteca Central Santa Mônica/UFU

\begin{tabular}{|c|c|c|c|c|}
\hline \multicolumn{2}{|r|}{ Serviço } & Quantidade & Valor Referência & Valor do Serviço \\
\hline \multirow{7}{*}{ Empréstimo } & Livros & 60.685 & $\mathrm{R} \$ 176,15$ & $\mathrm{R} \$ 10.689 .662,75$ \\
\hline & DVD & 796 & $\mathrm{R} \$ 90,33$ & $\mathrm{R} \$ 71.902,68$ \\
\hline & $\mathrm{CD}$ & 31 & $\mathrm{R} \$ 99,87$ & $\mathrm{R} \$ 3.095,97$ \\
\hline & Partituras & 339 & $\mathrm{R} \$ 65,82$ & $\mathrm{R} \$ 22.312,98$ \\
\hline & $\begin{array}{l}\text { Empréstimo Interbibliotecas } \\
\text { UFU (EIB) }\end{array}$ & 627 & $\mathrm{R} \$ 176,15$ & $\mathrm{R} \$ 110.446,05$ \\
\hline & $\begin{array}{l}\text { Empréstimo Entre Bibliotecas } \\
\text { (EEB) }\end{array}$ & 39 & $\mathrm{R} \$ 176,15$ & $R \$ 6.869,85$ \\
\hline & Dispositivos móveis & 1.439 & $\mathrm{R} \$ 762,94$ & $\mathrm{R} \$ 1.097 .870,66$ \\
\hline \multirow{3}{*}{ Consulta } & Livros & 69.075 & $\mathrm{R} \$ 176,15$ & $\mathrm{R} \$ 12.167 .561,25$ \\
\hline & Revistas & 0 & $\mathrm{R} \$ 0,00$ & $\mathrm{R} \$ 0,00$ \\
\hline & Jornais & 0 & $\mathrm{R} \$ 0,00$ & $\mathrm{R} \$ 0,00$ \\
\hline \multicolumn{2}{|l|}{ Reprografia } & 73.205 & $\mathrm{R} \$ 0,10$ & $\mathrm{R} \$ 7.320,50$ \\
\hline \multicolumn{2}{|c|}{ Comutação bibliográfica } & 33 & $\mathrm{R} \$ 6,60$ & $\mathrm{R} \$ 217,80$ \\
\hline \multirow{2}{*}{ Acesso } & Audio books & 47 & $\mathrm{R} \$ 2,18$ & $\mathrm{R} \$ 102,46$ \\
\hline & Música & 7.629 & $\mathrm{R} \$ 3,49$ & $\mathrm{R} \$ 26.625,21$ \\
\hline \multirow{4}{*}{ Download } & E-books & 12.949 & $\mathrm{R} \$ 101,81$ & $\mathrm{R} \$ 1.318 .337,69$ \\
\hline & $\begin{array}{l}\text { Documentos - Bases de } \\
\text { Dados assinadas }\end{array}$ & 27.582 & $\mathrm{R} \$ 6,60$ & $\mathrm{R} \$ 182.041,20$ \\
\hline & $\begin{array}{l}\text { Artigos - Portal de Periódicos } \\
\text { Capes/MEC }\end{array}$ & 384.983 & $\mathrm{R} \$ 6,60$ & $\mathrm{R} \$ 2.540 .887,80$ \\
\hline & $\begin{array}{l}\text { Biblioteca Digital de Teses e } \\
\text { Dissertações }\end{array}$ & 0 & $\mathrm{R} \$ 39,60$ & $\mathrm{R} \$ 0,00$ \\
\hline \multicolumn{2}{|c|}{$\begin{array}{l}\text { Uso de salas de estudo em grupo, multimídia e } \\
\text { de videoconferência }\end{array}$} & 12.542 & $\mathrm{R} \$ 35,00$ & $\mathrm{R} \$ 438.970,00$ \\
\hline \multirow{3}{*}{ Capacitação } & Visita orientada & 1.255 & $\mathrm{R} \$ 11,25$ & $\mathrm{R} \$ 14.118,75$ \\
\hline & Bases de dados & 1.709 & $\mathrm{R} \$ 10,00$ & $\mathrm{R} \$ 17.090,00$ \\
\hline & Normalização & 260 & $\mathrm{R} \$ 8,33$ & $\mathrm{R} \$ 2.165,80$ \\
\hline \multirow[b]{2}{*}{ Formação } & Bibliotecários e assistentes & 0 & $\mathrm{R} \$ 0,00$ & $\mathrm{R} \$ 0,00$ \\
\hline & $\begin{array}{l}\text { Participação em eventos, } \\
\text { reuniões }\end{array}$ & 13 & $\mathrm{R} \$ 1.303,57$ & $\mathrm{R} \$ 16.946,41$ \\
\hline \multicolumn{2}{|c|}{$\begin{array}{l}\text { Uso de computadores para pesquisa } \\
\text { acadêmica }\end{array}$} & 50.204 & $\mathrm{R} \$ 3,00$ & $\mathrm{R} \$ 150.612,00$ \\
\hline \multicolumn{2}{|c|}{ Serviços de Referência } & 54.877 & $\mathrm{R} \$ 22,92$ & $\mathrm{R} \$ 1.257 .780,84$ \\
\hline \multicolumn{2}{|c|}{ Catalogação na publicação } & 636 & $\mathrm{R} \$ 132,00$ & $\mathrm{R} \$ 83.952,00$ \\
\hline \multicolumn{2}{|c|}{ Informações por meio da página eletrônica } & 163 & $\mathrm{R} \$ 22,92$ & $\mathrm{R} \$ 3.735,96$ \\
\hline \multicolumn{4}{|l|}{ TOTAL } & $30.230 .626,61$ \\
\hline
\end{tabular}

Fonte: As autoras. 
Outro fator que influenciou o valor total foi o fato de não ter sido possível coletar dados para algumas categorias (destacadas em vermelho na Tabela 1). No caso de consultas e jornais estes dados não são coletados nem mesmo manualmente, não sendo possível fazer amostragem como apontado pelo CSIC (2012). O TEDE1, software da BDTD, não permite extração de dados estatísticos referente ao número de downloads. Estima-se que em breve será possível coletar estes dados considerando que o SISBI/UFU está em processo de migração das teses e dissertação do TEDE para o DSPACE (repositório institucional) que fornece estas informações.

Os resultados apontam o quão valioso são os serviços oferecidos pela Biblioteca Central Santa Mônica. Analisando os dados da Tabela 1, constata-se que na maioria das vezes os valores dos serviços superam o valor investido na aquisição de produtos que se transformam em serviços. Como exemplo destaca-se que basta apenas uma modalidade de empréstimo para superar em mais de 10 vezes o orçamento destinado à aquisição de material informacional para todo o SISBI/UFU.

$\mathrm{Na}$ contramão dos serviços supervalorizados, Reprografia não supera o montante investido na aquisição de dois scanners planetários, $\mathrm{R} \$ 126.000,00$ em 2013, sendo necessário neste contexto, aproximadamente 10 anos para 'pagar' cada equipamento. No entanto, a satisfação do usuário, a agilidade no atendimento, a contribuição com meio ambiente e a possibilidade de execução de serviços internos, como a digitalização de Teses e Dissertações ${ }^{13}$, justificam a aquisição do equipamento.

\section{CONSIDERAÇÕES FINAIS}

Para se alcançar o proposto para este trabalho: imputar valor econômico aos serviços oferecidos pela Biblioteca Central Santa Mônica, foram realizados vários estudos e análise destes serviços. Dentre os diversos desafios a definição de uma fórmula para precificação dos serviços foi considerada a tarefa mais complexa. A experiência de outras bibliotecas do exterior, especificamente no que diz respeito ao desenvolvimento/disponibilização de calculadoras para aplicação em bibliotecas, norteou as autoras facilitando em parte, a elaboração deste trabalho.

Como apontado nos objetivos, este estudo, não se esgota por aqui. A próxima etapa será a elaboração de um plano de aplicação para desenvolvimento de uma ferramenta para calcular os valores dos serviços informacionais com foco na realidade brasileira. Até a construção do plano de aplicação os serviços apontados neste trabalho bem como a fórmula de precificação, serão reavaliados pela equipe do Sistema de Bibliotecas da UFU que também contarão com o apoio dos colegas de outras instituições visando construir um instrumento que seja aplicável a qualquer biblioteca universitária brasileira.

13 Digitalização das Teses e Dissertações recebidas antes do dia 15 de setembro de 2005 quando passou a ser obrigatório a entrega da cópia eletrônica para inserção na Biblioteca Digital de Teses e Dissertações da UFU. 
A presente pesquisa apresentou importantes contribuições para as ações de gestão do SISBI/UFU pois permitiu a identificação de pontos que precisam ser melhorados na coleta de dados e ampliou o universo de argumentos que justificam a necessidade de maior investimento financeiro nas bibliotecas da UFU. Com a divulgação dos dados para a comunidade universitária da UFU, espera-se alcançar maior valorização dos serviços ofertados e da equipe profissional das bibliotecas e futuramente, com a implantação da calculadora, contribuir de abrangência global.

\section{¿CUANTO VALE LA INFORMACIÓN? CÁlCULO DEL VALOR ECONÓMICO DE LOS SERVICIOS DE UNA BIBLIOTECA}

\section{RESUMEN}

Los beneficios de los servicios ofrecidos por una unidad de información han sido caracterizados por los resultados deseados, por ejemplo, ante una pregunta formulada por el usuario, la respuesta efectiva está compuesta de valores con datos concretos considerados en términos monetarios, es decir, cuál es el costo de proporcionar tales servicios. Asignar y cuantificar el valor para cada uno de los servicios de información ofrecidos por las bibliotecas universitarias es una de las tareas de gestión más difíciles y menos aplicada en ambientes de información. Este trabajo tiene como objetivo asignar un valor económico a los servicios prestados por una biblioteca universitaria brasileña con el fin de desarrollar una herramienta que va a ayudar a los administradores de ella en la toma de decisiones y en la evaluación de las unidades informativas destinadas a garantizar la calidad de los servicios prestados.

PAlABRAS Clave: Costo de la información. Servicios de información. Biblioteca universitaria. Planificación. Evaluación. Universidad Federal de Uberlândia.

Submetido em: 04/11/2016

Aceito em: 19/12/2016

Publicado em: 19/12/2016

\section{REFERÊNCIAS}

ABBAS, K; GONÇALVES, M. N.; LEONCINE, M. Os métodos de custeio: vantagens, desvantagens e sua aplicabilidade nos diversos tipos de organizações apresentadas pela literatura. Contexto, Porto Alegre, v. 12, n. 22, p. 145-159, 2. sem. 2012. Disponível em: $\langle$ http://www.joinville.udesc.br/portal/professores/oliveira/materiais/Artigo_3.pdf $>$. Acesso em: 19 abr. 2016.

ALMEIDA, M. C. B. de A. Planejamento de bibliotecas e serviços de informação. 2. ed. rev. e ampl. Brasília, DF: Briquet de Lemos/Livros, 2005.

AVALIAÇÃO. In: CUNHA, M. B.; CAVALCANTI, C. R. de O. Dicionário de biblioteconomia e arquivologia. Brasília, DF: Briquet de Lemos, 2008. p. 41.

BALBINOTO NETO, G. Análise de custo benefício: aula 5. [2016]. Disponível em: <http://migre.me/tBjo1>. Acesso em: 19 abr. 2016.

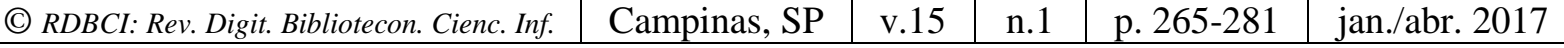


BARBALHO, C. R. S. Padrão de conformidade para unidades de informação: apresentação do modelo inglês. Informação \& Informação, Londrina, v. 2, n. 2, p. 47-54, jul./dez. 1997. Disponível em:

<http://www.uel.br/revistas/uel/index.php/informacao/article/viewFile/1626/1380 $>$. Acesso em: 19 abr. 2016.

BRASIL. Ministério de Planejamento, Orçamento e Gestão. Portal do software público brasileiro. Modelo de licença livre para o código-fonte, proteção da identidade original entre nome, marca, código-fonte, documentação e outros artefatos relacionados por meio do modelo de Licença Pública de Marca - LPM. Brasília, DF, [2016a]. Disponível em: <https://softwarepublico.gov.br/social/spb/o-que-e-o-software-publico>. Acesso em: 19 abr. 2016.

CONSEJO SUPERIOR DE INVESTIGACIONES CIENTIFICAS (Espanha). Red de Bibliotecas y Archivos. Unidad de Recursos de Información Científica para la Investigación. Valoración y uso de las bibliotecas. Madrid, 2012. 1 arquivo em PDF, 90,03 KB.

DHOLAKIA, N.; MUNDORF, N.; DHOLAKIA, R. R. Novos serviços de informação e comunicação: um quadro de referência estratégico. Ciência da Informação, Brasília, DF, v. 26, n.3, set./dez. 1997. Disponível em: $<$ http://www.scielo.br/scielo.php?script=sci_arttext\&pid=S0100-19651997000300002>. Acesso em: 19 abr. 2016.

GÜNTHER, H. Pesquisa qualitativa versus pesquisa quantitativa: esta é a questão? Psicologia: teoria e pesquisa, Brasília, DF, v. 22, n.2, p. 201-210, maio/ago. 2006.

INTERNATIONAL STANDARD ORGANIZATION. ISO 11620: Information and documentation: Library performance indicators. Geneva, 2014.

LANCASTER, F. W. Avaliação de serviços de bibliotecas. Brasília, DF: Briquet de Lemos, 1996.

LEITE, J. S. G.; SOUZA, E. D. A gestão da informação e do conhecimento nas organizações. Ciência da Informação em Revista, Maceió, v. 1, n. 1, p. 12-16, jan./abr. 2014. Disponível em: <http://www.seer.ufal.br/index.php/cir/article/view/1299/900>. Acesso em: 19 abr. 2016.

MARCHIORI, P. Z. Gestão da informação: fundamentos, componentes e desafios contemporâneos. In: SOUTO, L. F. Gestão da informação e do conhecimento: práticas e reflexões. Rio de Janeiro: Interciência, 2014. cap. 2, p. 27-45.

MARCONI, M. de A.; LAKATOS, E. M. Técnicas de pesquisa: planejamento e execução de pesquisas, amostragens e técnicas de pesquisa, elaboração, análise e interpretação de dados. 2. ed. São Paulo: Atlas, 1990.

MARTINS, E. Contabilidade de custos. São Paulo: Atlas, 2000.

UNIVERSIDADE FEDERAL DE UBERLÂNDIA. Sistema de Bibliotecas. Estatística 2015. Uberlândia, 2106. Disponível em: 〈http://www.bibliotecas.ufu.br/node/835>. Acesso em: 19 abr. 2016.

\begin{tabular}{l|l|l|l|l|l|} 
(C) RDBCI: Rev. Digit. Bibliotecon. Cienc. Inf. & Campinas, SP & v.15 & n.1 & p. 265-281 & jan./abr. 2017 \\
\hline
\end{tabular}


UNIVERSIDADE FEDERAL DE UBERLANDIA. Faculdade de Educação. Programa de Pós-Graduação em Tecnologias, Comunicação e Educação. Diretrizes para elaboração do relatório de qualificação e relatório final (dissertação, plano de aplicação ou produto). Texto de Mirna Tonus et al. Uberlândia, 2014. Disponível em: $<$ http://www.ppgce.faced.ufu.br/sites/ppgce.faced.ufu.br/files/Anexos/Bookpage/DIRETRIZ ES_QUALIFICACAO_DEFESA_PPGCE.pdf>. Acesso em 19 abr. 2016.

UNIVERSITY OF WEST FLORIDA. Haas Center. Taxpayer Return On Investiment in Florida Public Libraries: 2013. Pensacola, 2013. Disponível em: $<$ http://roi.info.florida.gov/Content/PDFs/Studies/Library\%20ROI\%202013.pdf >. Acesso em: 18 nov. 2016.

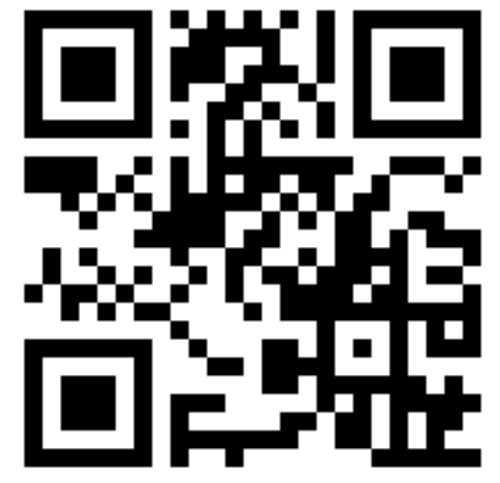

